OPEN ACCESS

Edited by:

Dawei Wang,

RWTH Aachen University, Germany

Reviewed by:

Yanjun Qiu,

Southwest Jiaotong University, China

Leilei Chen,

Southeast University, China

Yue Xiao,

Wuhan University of Technology,

China

Bin Hong,

Harbin Institute of Technology, China

*Correspondence:

Shifa Xu

xu-sf@126.com

Specialty section:

This article was submitted to Structural Materials,

a section of the journal

Frontiers in Materials

Received: 16 October 2020

Accepted: 15 December 2020

Published: 21 January 2021

Citation:

Xu Y, Lv X, Ma C, Liang F, Qi J, Chou Z and Xu S (2021) Shear Fatigue

Performance of Epoxy Resin

Waterproof Adhesive Layer on Steel

Bridge Deck Pavement.

Front. Mater. 7:618073.

doi: $10.3389 /$ fmats.2020.618073

\section{Shear Fatigue Performance of Epoxy Resin Waterproof Adhesive Layer on Steel Bridge Deck Pavement}

\author{
Ying $X u^{1,2}$, Xinpeng $L v^{1}$, Chunfeng $M a^{3}$, Fengming Liang ${ }^{3}$, Jiafei $Q i^{3}$, Zhijing Chou ${ }^{1}$ and \\ Shifa $X u^{1,2 *}$
}

${ }^{1}$ School of Civil Engineering and Transportation, Beijing University of Civil Engineering and Architecture, Beijing, China, ${ }^{2}$ Beijing Urban Transportation Infrastructure Engineering Technology Research Center, Beijing, China, ${ }^{3}$ Henan Taihui Expressway Construction Co., Ltd., Henan, China

In this study, the effects of temperature, shear stress, and coating quantity of waterproof adhesive layer on the shear fatigue performance of a steel bridge deck pavement were investigated. Direct shear fatigue tests of a pavement comprising an epoxy resin waterproof adhesive layer with stone matrix asphalt were conducted at different temperatures, stress levels, and coating quantities. The results show that temperature and stress have significant effects on the shear fatigue life. With increasing temperature and stress, the shear fatigue life of the waterproof adhesive layer decreased gradually. Therefore, for steel bridge deck pavements under high temperatures and heavy loads, the use of asphalt waterproof adhesive layers or pavement layers should be evaluated carefully while limiting the traffic of heavily loaded vehicles. Shear failure occurs at the waterproof adhesive layer-pavement interface and not at the steel-waterproof adhesive layer interface. The shear strength of the epoxy resin waterproof adhesive layer is mainly provided by the bond strength between the waterproof adhesive and pavement mixture as well as the interlocking force between the cured epoxy resin and the bottom interface of uneven pavement mixture. The shear strength increases with the coating quantity of the waterproof adhesive layer; however, after reaching the maximum value, the shear strength becomes stable. In contrast, the interlaminar shear fatigue life increases continuously with the coating quantity of the waterproof adhesive layer. Appropriately increasing the coating quantity is beneficial for improving the resistance of the waterproof adhesive layer to interlaminar shear fatigue failure.

Keywords: waterproof adhesive layer interface, epoxy resin adhesive, shear fatigue performance, interface failure, steel bridge deck

\section{INTRODUCTION}

In the construction of transportation infrastructure, steel bridges are used extensively because of their light weight, low cost, and ease of construction (Liu et al., 2016). The quality of the steel bridge deck pavement not only affects driving safety and comfort, it also affects the service life and investment benefit of a bridge system. However, owing to the complex stresses and poor thermal insulation of steel bridges, the waterproof adhesive layer interface between the steel plate and the asphalt mixture is usually the weakest part of a steel bridge deck pavement structure (Yao et al., 2016), which can easily cause interlayer displacement problems resulting from higher interlayer shear effects during service (Song et al., 2016; Wang et al., 2018). 
The shear failure modes of the waterproof adhesive layer interface in steel deck pavement structures can be classified into shear strength failure (Medani 2001; Bocci and Canestrari 2012; Bocci and Canestrari 2013; Ge et al., 2014; Medani et al., 2008; Qiu et al., 2019) and shear fatigue failure under repeated loads (Boudabbous et al., 2013; Liu et al., 2016; Song et al., 2016). The failure of the waterproof adhesive layer is usually attributed to insufficient shear strength. Recent research has revealed that the interlayer bonding state of the bridge deck pavement is affected by the environment during service and is subjected to recurring wheel loads and vibration loads ( $\mathrm{Li}$ and Yu 2014). Thus, it is in the state of overlapping stress changes for long periods, and experiences shear fatigue failure ( $\mathrm{Li}$ and $\mathrm{Yu}$ 2014). Therefore, the traditional experimental method of shear strength failure cannot reflect the behavior of interlaminar shear fatigue.

Researchers have developed various test methods and devices to study the shear fatigue behavior of steel deck pavement structures. Currently, four methods are commonly used to evaluate the shear fatigue performance between the layers of a pavement structure: direct shear fatigue, four-point shear fatigue, slant shear fatigue, and double shear fatigue (Diakhate et al., 2006; Boudabbous et al., 2013; Li et al., 2014; Li and Yu 2014; Tozzo et al., 2014; Rahman et al., 2019). The double shear fatigue test method is often used for determining the shear fatigue damage and viscoelastic parameters of asphalt mixtures; it is less frequently used to study the interlayer shear fatigue performance between different material interfaces (Boudabbous et al., 2013). The slant shear fatigue test method can simulate the effect of vertical and horizontal forces simultaneously, but the loading angles of the forces cannot be adjusted, and the loading mode will intensify the stress concentration effect, resulting in inaccurate test results (Diakhate et al., 2006; Li et al., 2014; Li and Yu 2014). The four-point shear fatigue test method can produce a pure shear action at the interface of the specimen without superposition of the bending moment action and can apply normal stress to the interface at the same time. However, the procedure of this test method is more complex; hence, it is less commonly used at present (Rahman et al., 2019). The direct shear fatigue test method is easy to perform and can apply normal and shear stresses simultaneously. The accuracy of its test results is high; consequently, it has become the preferred test method for studying the shear fatigue performance of waterproof adhesive layers on steel bridge deck pavements (Tozzo et al., 2014).

At present, the research on the shear fatigue performance between the layers of a pavement structure is mainly focused on the asphalt concrete pavement structure and concrete bridge deck pavement structure (Li and Yu 2014; Tozzo et al., 2014; Song et al., 2016; Wang et al., 2017; Rahman et al., 2019). Research on steel deck pavement structures is relatively sparse. Wang et al. suggested that the interlaminar shear fatigue stress should be considered as an important design index in asphalt pavement structure design. $\mathrm{Li}$ et al. conducted shear fatigue tests on waterproof adhesive layers with different materials in a concrete bridge deck pavement, and found that the epoxy resin waterproof adhesive layer has better anti-fatigue performance. Qiu et al. (2019) conducted a shear fatigue test on a steel bridge deck with modified asphalt concrete as the pavement layer and five types of waterproof adhesive layers. Their results showed that the setting of waterproof adhesive layers could significantly improve the shear fatigue life of the steel bridge deck pavement. Liu et al. (2016) performed shear fatigue tests on a steel deck pavement system with an SMA-13 pavement and a resin asphalt adhesive layer at three stress levels. It was revealed that the shear fatigue life decreased with increasing stress.

Regarding the influencing factors of the interlaminar shear fatigue life of pavement structures, Boudabbous et al. (2013) studied the shear fatigue performance of asphalt mixtures from the perspective of energy dissipation. They defined the plateau value as an index to evaluate the shear fatigue performance of the materials at different temperatures and stresses. Rahman et al. (2019) investigated composite beam specimens composed of SMA and asphalt concrete. They found that temperature and stress are significant factors affecting the shear fatigue life. The shear fatigue performance of the waterproof adhesive layer interface decreases with increasing temperature or stress. Wang et al. (2017) studied the shear fatigue performance of a thermoplastic waterproof adhesive layer material in an asphalt pavement, and obtained the shear fatigue life equation through temperature correction. Diakhate et al. (2011) investigated the influence of a waterproof adhesive layer on the interfacial shear fatigue performance of an asphalt mixture subjected to temperature and stress. They concluded that the waterproof adhesive layer has a considerable effect on the interlayer shear fatigue. Therefore, temperature and stress are the leading factors affecting the interlaminar shear fatigue life.

In summary, most of the existing studies are focused on pavements or concrete deck pavement structures. The number of studies on the interlaminar shear fatigue performance of steel deck pavements is fewer than that on the shear performance of waterproof adhesive layer materials. However, the shear fatigue life of bridge deck pavement is more sensitive than that of asphalt pavement (Chang et al., 2016). Moreover, the shear fatigue performance of steel deck pavement structures with epoxy resin as a waterproof adhesive layer is rarely studied. Compared with the traditional asphalt mixture, SMA has excellent high-temperature stability, low-temperature crack resistance, and deformation compatibility. The epoxy resin has high bond strength and is little affected by temperature, which is beneficial to enhance the bond between the pavement structure layer and steel plate and reduce defects such as interlayer void (Chen et al., 2020). Therefore, there are many steel deck pavement structures in China with SMA as the pavement layer and epoxy resin as the waterproof adhesive layer (Chen and Zhang 2004).

This study investigated the interlaminar shear fatigue performance of a typical steel deck pavement structure. Specifically, direct shear fatigue tests were performed to determine the shear resistance of a steel deck pavement considering the influence of temperature, stress, and coating quantity of the waterproof adhesive layer. The variation of shear fatigue life under different conditions was analyzed and the shear fatigue life equation of the waterproof adhesive layer 


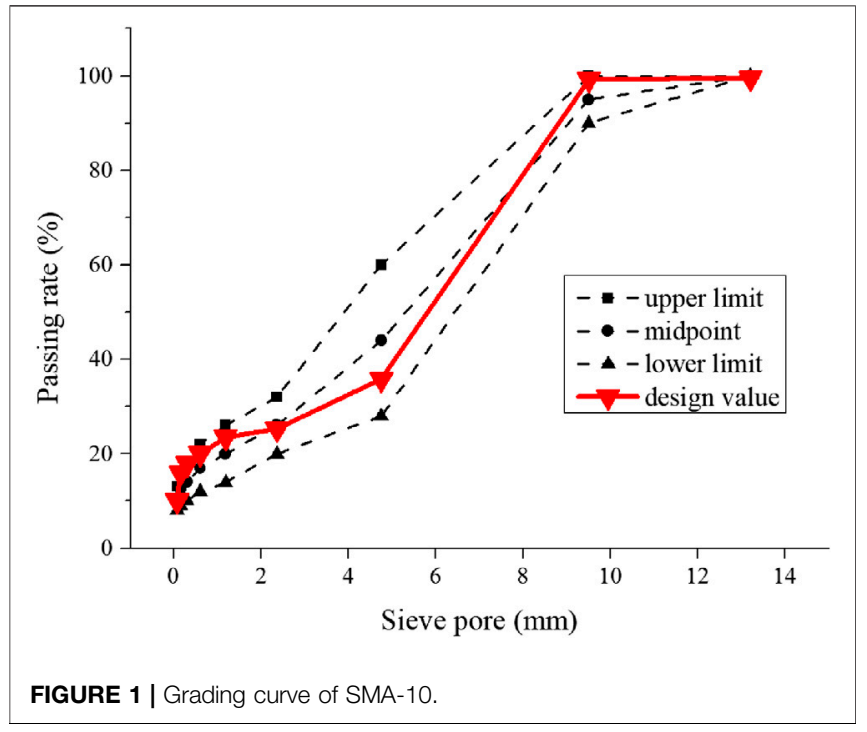

and bituminous mixtures for highway engineering (JTG E20-2011, 2011), are presented in Table 1. The optimal asphalt content of SMA-10 was determined as $6.2 \%$ using the Marshall design method.

\subsubsection{Waterproof Adhesive Layer Material}

The waterproof adhesive layer material used in this study was thermosetting epoxy resin adhesive type I (ER). The ER was composed of components $\mathrm{A}$ and $\mathrm{B}$, with the mass ratio of component $\mathrm{A}$ to component $\mathrm{B}$ at 2:1. After the two components were mixed evenly, the mixture was applied in two layers. The first layer was coated with $1 / 3$ of the total ER coating quantity, and breakstone with a particle size of $0.3-0.6 \mathrm{~mm}$ was sprayed at $300-400 \mathrm{~g} / \mathrm{m}^{2}$. When the first layer of the waterproof adhesive was in the tack-free state, the second layer was applied, and breakstone with a particle size of $1.18-2.36 \mathrm{~mm}$ was sprayed at $500-800 \mathrm{~g} / \mathrm{m}^{2}$. Subsequently, when the second layer was in the tack-free state, the SMA-10

TABLE 1 | Performance indices and test results of SBS modified asphalt.

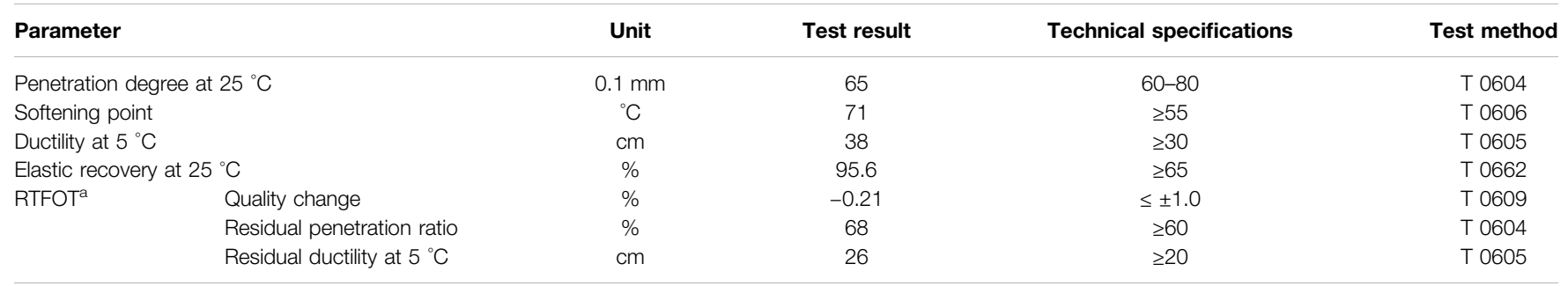

${ }^{a}$ Rolling thin film oven test.

was established. Furthermore, the failure mechanism of the waterproof adhesive layer under different combinations of factors was examined. The objective of the study is to recommend measures for enhancing the design of steel deck pavement structures.

\section{MATERIALS AND METHODS}

\subsection{Materials}

\subsubsection{Pavement Materials}

The research subject was the interlaminar shear performance between the pavement and steel plate. Modified asphalt SMA-10 and epoxy resin adhesive were used as the pavement layer and waterproof adhesive layer, respectively. SBS modified asphalt was composed of asphalt 70\# and SBS modifier. The epoxy resin was type I epoxy resin binder, which is a kind of commercial adhesive that is used for steel bridge deck pavement. The specification of the steel plate was Q235.

The gradation of the SMA-10 is illustrated in Figure 1. Basalt was used as the coarse aggregate, limestone as fine aggregate and mineral powder, lignin fiber as fiber, and SBS modified asphalt as asphalt binder. The performance indices of the asphalt, which was evaluated in accordance with Standard test methods of bitumen asphalt mixture was overlaid. The ER performance was tested according to Specifications for design and construction of pavement on highway steel deck bridge (JTG T3364-02-2019, 2019); the technical indices are listed in Table 2.

\subsection{Test Methods}

The relationship between the coating quantity of the ER waterproof adhesive and shear strength was established through shear strength tests. The optimum coating quantity of the waterproof adhesive layer was preliminarily determined. At this coating quantity, the effects of temperature and shear stress on the interlaminar shear fatigue properties were tested and analyzed through direct shear fatigue tests. Then, under the same shear stress, the influence of temperature and the waterproof adhesive layer quantity on the shear fatigue life was tested and analyzed.

\subsubsection{Shear Strength Test Method}

The shear strength test was carried out in accordance with the test method described in Appendix C of Specifications for design and construction of pavement on highway steel deck bridge (JTG T3364-022019, 2019). The test used nine different quantities of the ER waterproof adhesive layer $\left(0.7-1.5 \mathrm{~kg} / \mathrm{m}^{2}\right.$, increments of $\left.0.1 \mathrm{~kg} / \mathrm{m}^{2}\right)$. The test temperature and shear failure displacement were set as $25^{\circ} \mathrm{C}$ and $5 \mathrm{~mm}$, respectively. 
TABLE 2 | Performance indices and test results of epoxy resin.

\begin{tabular}{|c|c|c|c|}
\hline Parameter & Technical specifications & Test result & Test method \\
\hline Bond strength with steel plate (MPa) & $\geq 5.0$ & 36.3 & Appendix B of JTG T3364-02-2019 (2019) \\
\hline Tensile strength at $23^{\circ} \mathrm{C}(\mathrm{MPa})$ & $\geq 10.0$ & 12 & Appendix B of JTG T3364-02-2019 (2019) \\
\hline
\end{tabular}

TABLE 3 | Direct shear fatigue test parameters.

\begin{tabular}{|c|c|c|}
\hline & Test group 1 & Test group 2 \\
\hline Loading mode & Stress control & Stress control \\
\hline Loading waveform and frequency & Sine wave, $10 \mathrm{~Hz}$ & Sine wave, $10 \mathrm{~Hz}$ \\
\hline Shear stress (MPa) & $0.28,0.42,0.56,0.70$ & 0.42 \\
\hline Coating quantity of waterproof adhesive layer $\left(\mathrm{kg} / \mathrm{m}^{2}\right)$ & Optimal quantity & $0.5,0.9,1.3,1.7$ \\
\hline Temperature $\left({ }^{\circ} \mathrm{C}\right)$ & $-10,15,25,50,70$ & $15,30,50$ \\
\hline Failure criterion & Shear displacement reaches $5 \mathrm{~mm}$ & Shear displacement reaches $5 \mathrm{~mm}$ \\
\hline
\end{tabular}

The specimen fabrication simulated the actual construction process, i.e., coating two layers of the ER waterproof adhesive layer on a $100 \times 100 \times 16 \mathrm{~mm}$ steel plate, and then placing the plate in a rutting testing mold at $175^{\circ} \mathrm{C}$. SMA-10 asphalt mixture at $175^{\circ} \mathrm{C}$ was poured into the rutting testing mold and compacted. Finally, after the rutting testing mold was cooled, a specimen with dimensions of $100 \times 100 \times 50 \mathrm{~mm}$ was cut. The average values of five parallel tests were taken as the experimental results. The shear strength was calculated using Eq. 1:

$$
\tau=\frac{F}{S} \times \sin \alpha
$$

where $\tau$ is the shear strength (MPa), $\alpha$ is the shear angle $\left({ }^{\circ}\right), F$ is the maximum load at failure $(\mathrm{N})$, and $S$ is the bottom surface area of the steel plate $\left(\mathrm{mm}^{2}\right)$.

\subsubsection{Direct Shear Fatigue Test Method}

To investigate the effects of temperature, stress, and coating quantity of the waterproof adhesive layer on the shear failure performance of the steel deck pavement, two groups of tests were designed and conducted in this study. In the first group, the coating quantity of the waterproof adhesive layer was maintained at the optimal quantity. Different temperatures and stresses were selected for the tests. Considering the actual temperature range of steel bridge decks, the test temperatures were set as $-10^{\circ} \mathrm{C}, 15^{\circ} \mathrm{C}$, $25^{\circ} \mathrm{C}, 50^{\circ} \mathrm{C}$, and $70^{\circ} \mathrm{C}$. In a previous finite element analysis conducted by the team members, the maximum shear stress of the waterproof adhesive layer under a standard axle load of $100 \mathrm{kN}$ was found to be approximately 1.4 MPa (Chou 2020). The values of the stress ratio in this test ranged from 0.2 to 0.5 (increasing by 0.1 ); therefore, the stresses were $0.28,0.42,0.56$, and $0.70 \mathrm{MPa}$, respectively.

In the second group of tests, the stress was set as $0.42 \mathrm{MPa}$, and different temperatures and coating quantities of the waterproof adhesive layer were selected. The test temperatures were $15^{\circ} \mathrm{C}$, $30^{\circ} \mathrm{C}$, and $50^{\circ} \mathrm{C}$, and the quantities of the waterproof adhesive layer were $0.5 \mathrm{~kg} / \mathrm{m}^{2}, 0.9 \mathrm{~kg} / \mathrm{m}^{2}, 1.3 \mathrm{~kg} / \mathrm{m}^{2}$, and $1.7 \mathrm{~kg} / \mathrm{m}^{2}$. The specific parameters are listed in Table 3 .
A test device based on a universal testing machine (UTM) was used for the direct shear fatigue test, as shown in Figure 2A. The device was divided into left and right parts. The left half could be moved up or down to fix the pavement layer (Figure 2B), whereas the right half could not be moved and was used to fix the steel plate (Figure 2C). Both parts were circular to ensure that the specimen could be evenly stressed. In this test, a cylindrical steel base with a diameter of $100 \mathrm{~mm}$ and a height of $50 \mathrm{~mm}$ was used. The height of the pavement mixture specimen was $40 \mathrm{~mm}$, and the total height of the formed composite specimen was $90 \mathrm{~mm}$ (Figure 2D). The average values of five parallel tests were taken as the experimental results.

\section{RESULTS AND DISCUSSION}

\subsection{Effect of Adhesive Quantity on Shear Strength}

The relationship between the coating quantity of the waterproof adhesive layer and shear strength in the shear strength test is depicted in Figure 3. In the range of $0.7-1.5 \mathrm{~kg} / \mathrm{m}^{2}$, the shear strength first increases with the coating quantity; then, it decreases and finally stabilizes. At the coating quantity of $1.3 \mathrm{~kg} / \mathrm{m}^{2}$, the maximum shear strength is $2.11 \mathrm{MPa}$. Subsequently, any increase in the coating quantity causes the shear strength to decrease slightly, but it stabilizes at approximately 2.07 MPa.

For an asphalt waterproof adhesive layer, Liu et al. found that the shear strength of the interface between the steel plate and pavement increases with the coating quantity of the adhesive layer (Liu et al., 2017). However, after reaching the optimal value, a further increase in the coating quantity leads to a continuous decrease in shear strength. As a thermoplastic material, any excessive quantity of the asphalt waterproof adhesive will form a sliding layer at the interface. This sliding layer decreases the friction resistance between the layers, thus significantly reducing the interlaminar shear strength. However, after the shear strength of a thermosetting waterproof adhesive has reached the optimal quantity, it is no longer affected and remains unchanged. 

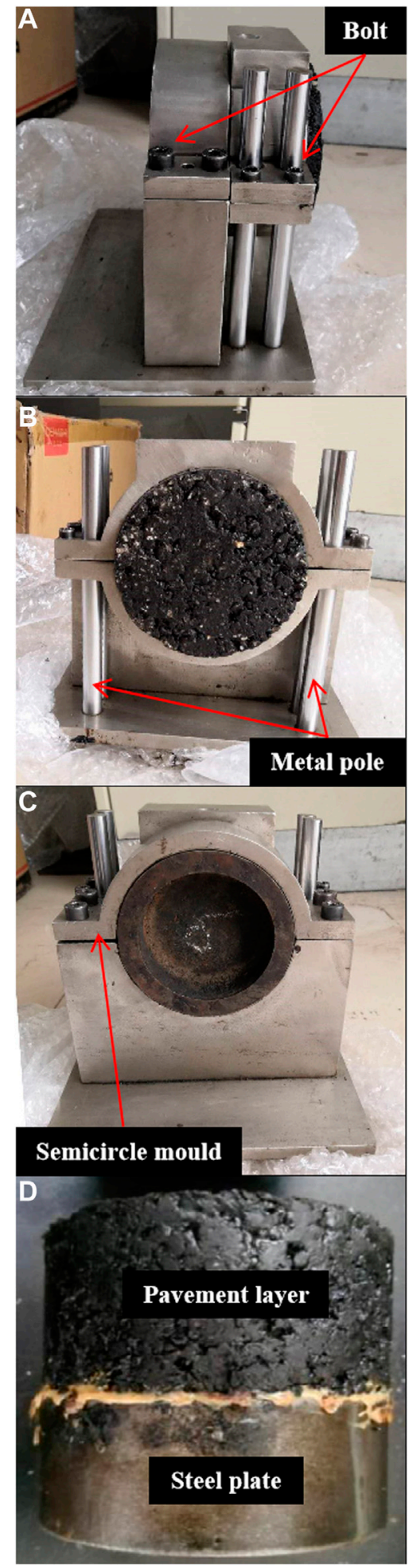

FIGURE 2 | Direct shear fatigue test device.

The epoxy resin waterproof adhesive used in this study is a thermosetting material, and its shear strength variation is consistent with the result of the study by Liu et al. This is

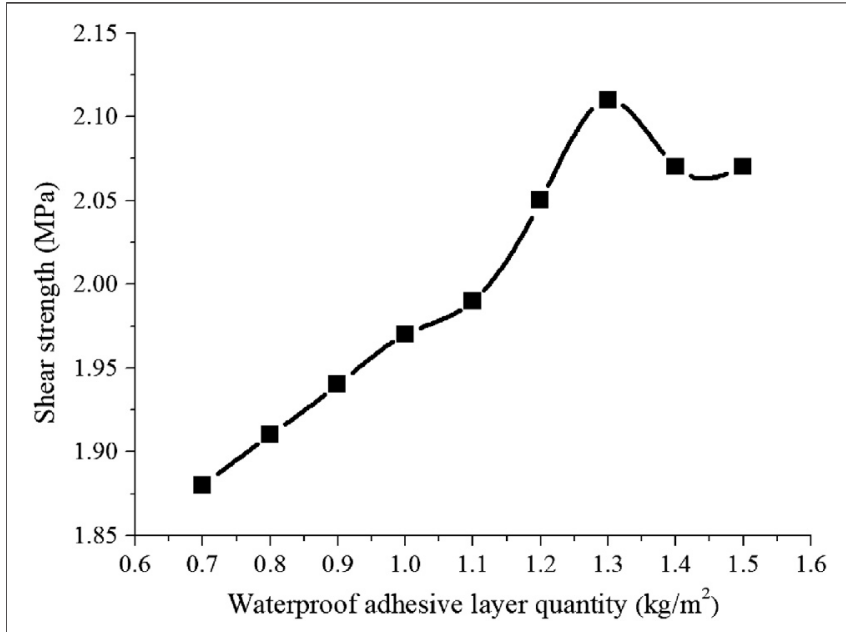

FIGURE 3 | Shear strength variation with adhesive layer quantity.

because after paving and compacting, the interface between the pavement mixture and the steel plate becomes uneven (Figure 4). With any increase in the coating quantity of the waterproof adhesive layer, a larger amount of adhesive fills the uneven surface of the asphalt mixture. This increases the bonding area between the waterproof adhesive and asphalt mixture, which correspondingly increases the bond strength. After the asphalt mixture surface is completely filled with the waterproof adhesive, the optimal adhesive quantity is achieved. Subsequently, increasing further the epoxy resin waterproof adhesive quantity no longer increases the bonding area between the waterproof adhesive and pavement mixture. Moreover, owing to the high strength of the cured epoxy resin, the extra epoxy resin will not form a sliding layer between the layers similar to that of the asphalt waterproof adhesive layer. In addition, at the uneven interface between the waterproof adhesive layer and pavement layer, the interlocking force produced by the two materials will also contribute to the shear stress damage resistance. Therefore, the shear strength will not continue to decline after reaching the optimum adhesive quantity, but will be maintained at a high level.

\subsection{Effect of Temperature and Stress on Shear Fatigue Life 3.2.1 Significance Analysis}

Under the optimum quantity of waterproof adhesive layer, the values of shear fatigue life at different temperatures and stresses are presented in Table 4.

The temperature and stress were analyzed by a two-way analysis of variance at $95 \%$ significance level. The $F$ values of temperature and stress are 6.04 and 18.41, respectively, which are greater than the $F_{\alpha}(0.05)$ values. It means that both factors have significant effects on the shear fatigue life.

\subsubsection{Impact Trend Analysis}

The shear fatigue life curves at different temperatures and stresses are displayed in Figure 5. It can be observed from Figure 5A that 


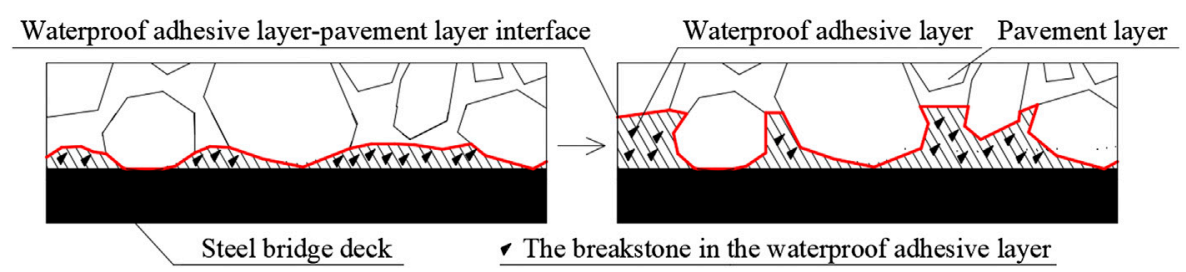

FIGURE 4 | Waterproof adhesive layer interface.

TABLE 4 I Shear fatigue life $\left(\times 10^{4}\right)$ at different temperatures and stresses.

\begin{tabular}{lcccc} 
Temperature ( $\left.{ }^{\circ} \mathbf{C}\right)$ & \multicolumn{4}{c}{ Stress $(\mathbf{M P a})$} \\
\cline { 2 - 5 } & $\mathbf{0 . 2 8}$ & $\mathbf{0 . 4 2}$ & $\mathbf{0 . 5 6}$ & $\mathbf{0 . 7 0}$ \\
\hline-10 & 69.34 & 31.25 & 16.87 & 9.57 \\
15 & 67.30 & 28.85 & 15.47 & 8.74 \\
25 & 65.73 & 25.89 & 13.83 & 7.28 \\
50 & 43.30 & 11.07 & 3.36 & 0.94 \\
70 & 5.00 & 0.86 & 0.53 & 0.15 \\
\hline
\end{tabular}

the shear fatigue life at the same temperature decreases with any increase in stress, and the rate of decrease gradually reduces. The influence of temperature on the rate of change of shear fatigue life at three different stress ranges of $0.28-0.42 \mathrm{MPa}, 0.42-0.56 \mathrm{MPa}$, and $0.56-0.70 \mathrm{MPa}$ is explained as follows:

$$
R_{i}=\left(N_{i-1}-N_{i}\right) /\left(\tau_{i}-\tau_{i-1}\right) \quad(i=1,2,3)
$$

where $R_{1}, R_{2}$, and $R_{3}$ represent the change rates of shear fatigue life in the stress ranges of $0.28-0.42 \mathrm{MPa}, 0.42-0.56 \mathrm{MPa}$, and 0.56-0.70 MPa, respectively; $N_{0}, N_{1}, N_{2}$, and $N_{3}$ are the shear fatigue lives at $0.28,0.42,0.56$, and $0.70 \mathrm{MPa}$, respectively; and $\tau_{0}$, $\tau_{1}, \tau_{2}$, and $\tau_{3}$ represent the shear stresses at $0.28,0.42,0.56$, and $0.70 \mathrm{MPa}$, respectively.

The change rates of shear fatigue life at the different stress ranges and temperatures were calculated using Eq. 2. As illustrated in Figure 5C, regardless of the temperature value, the change rate of shear fatigue life in the low stress range $(0.28-0.42 \mathrm{MPa})$ is higher than that in the medium stress range $(0.42-0.56 \mathrm{MPa})$ and high stress range $(0.56-0.70 \mathrm{MPa})$. This indicates that the sensitivity of shear fatigue life decreases with increasing stress. In the same stress range, increasing temperature causes a gradual decrease in the change rate of the shear fatigue life. The change rate of the shear fatigue life changes slightly in the range of $-10^{\circ} \mathrm{C}$ to $50^{\circ} \mathrm{C}$. However, when the temperature increases from $50^{\circ} \mathrm{C}$ to $70^{\circ} \mathrm{C}$, the change rate of the shear fatigue life decreases sharply.

As shown in Figure 5B, under the same stress, the shear fatigue life decreases with increasing temperature, and the rate of decrease gradually increases. For similar interface conditions, an increase in temperature leads to a decrease in shear strength, which means that a high temperature is more likely to cause interface failure. It can also be seen from the figure that there are two stages of shear fatigue life variation with temperature. In the first stage $\left(-10^{\circ} \mathrm{C}\right.$ to $\left.25^{\circ} \mathrm{C}\right)$, the shear fatigue lives at different
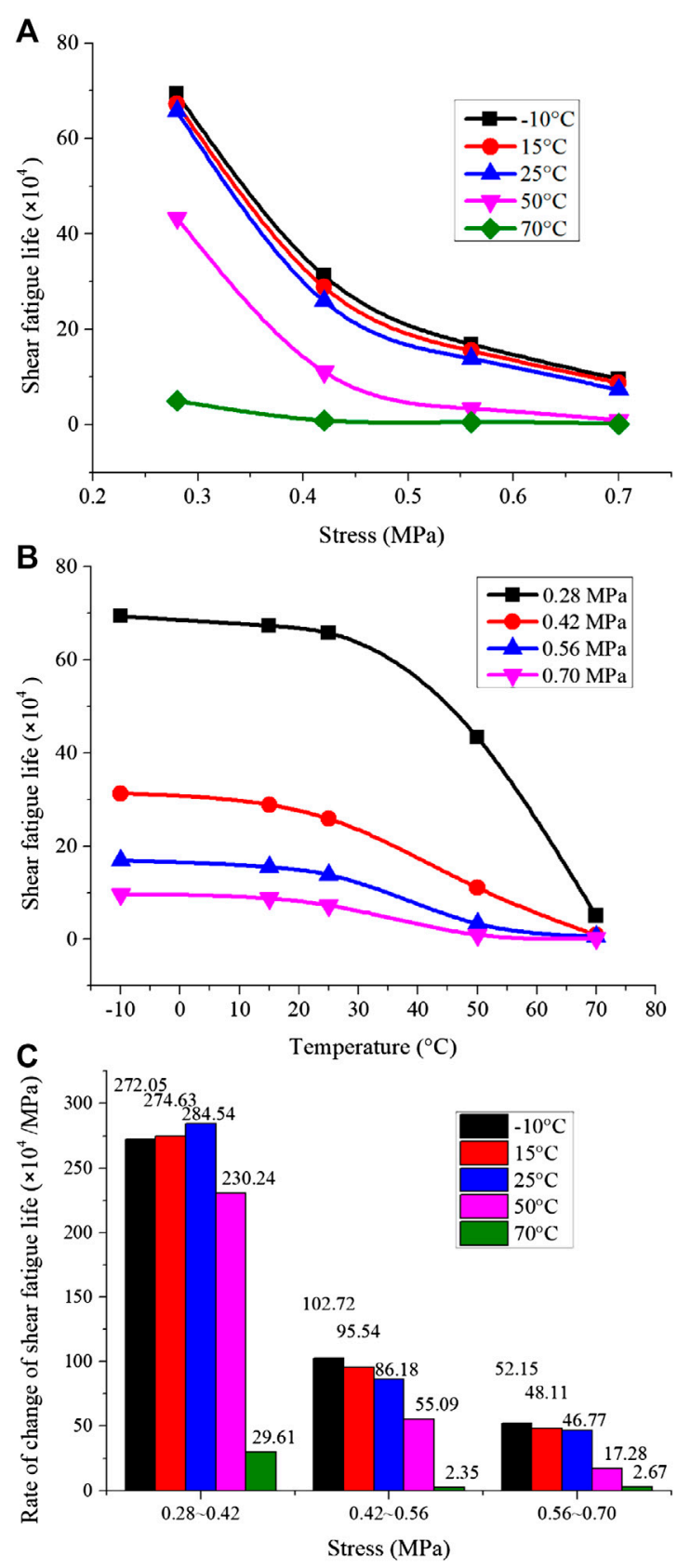

FIGURE 5 | Stress and temperature effect on shear fatigue life. 


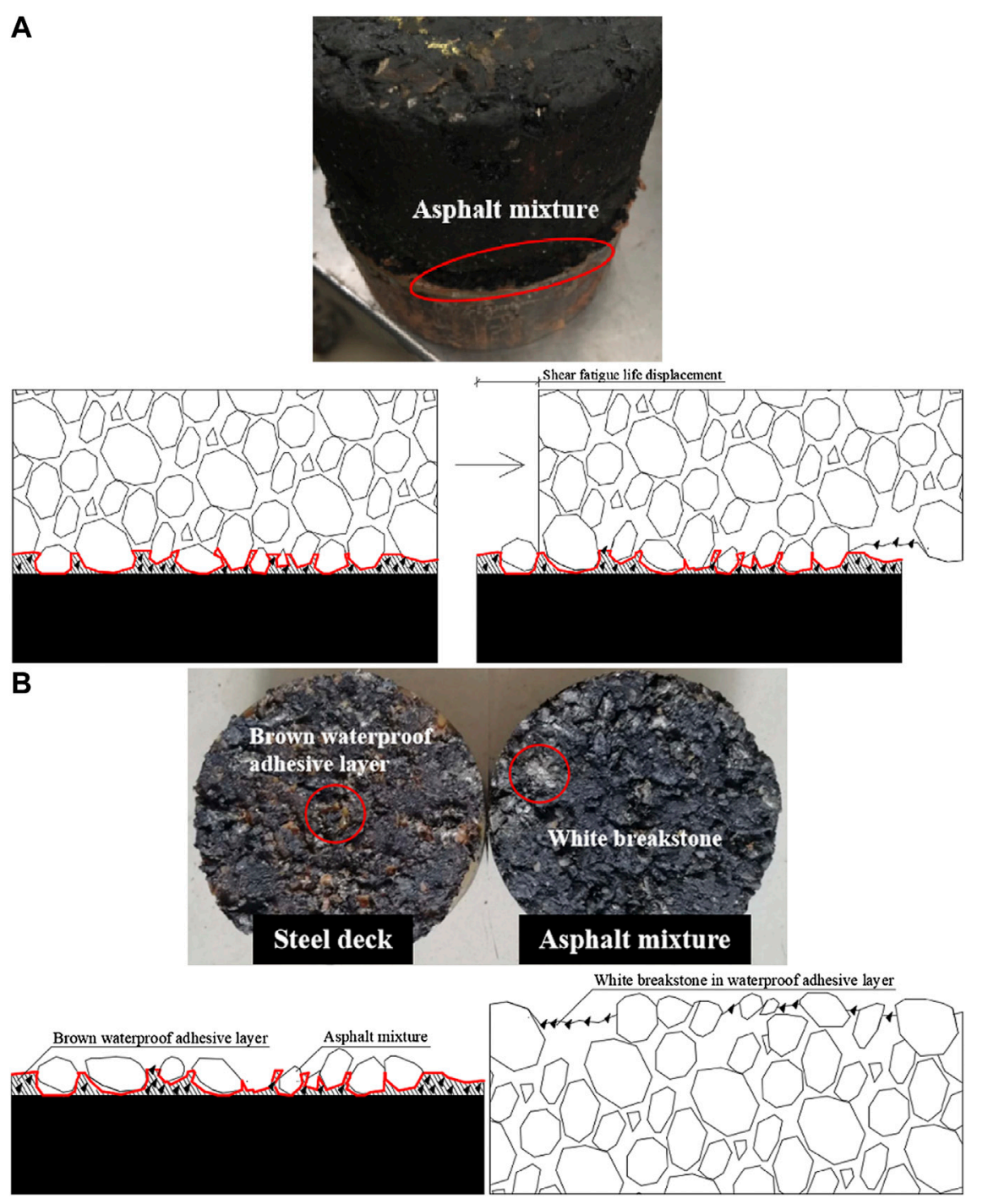

FIGURE 6 | Two kinds of shear fatigue failure states of specimens.

temperatures have negligible differences. Conversely, in the second stage $\left(25^{\circ} \mathrm{C}-70^{\circ} \mathrm{C}\right)$, the shear fatigue lives decrease sharply. At $70{ }^{\circ} \mathrm{C}$, regardless of the stress value, the shear fatigue life remains small. Chang et al. (2016) also found that the shear fatigue life of the thermosetting waterproof adhesive layer decreased sharply with the increase of the stress level at $60^{\circ} \mathrm{C}$. When the stress level increased from 0.2 to 0.7 , the shear fatigue life decreased by $99.3 \%$.

The above observations can be explained by the following analysis. The pavement material selected in this study is SMA, and the softening point of modified asphalt is $71^{\circ} \mathrm{C}$. When the temperature is in the range of $50^{\circ} \mathrm{C}-70^{\circ} \mathrm{C}$, it is very close to the softening point of modified asphalt. At this point, the bond strength between the pavement layer and the epoxy resin waterproof adhesive layer is very weak. This leads to a sharp decrease in the interlayer shear fatigue life. In many parts of China, the temperature in summer may be above $35^{\circ} \mathrm{C}$ for a long period. The maximum temperature of the pavement can reach $68.5^{\circ} \mathrm{C}$, and the temperature can exceed $50^{\circ} \mathrm{C}$ per day for more than $9 \mathrm{~h}$ (Shen et al., 2018). If the steel deck pavement is subjected to large traffic volume or heavy traffic load, the pavement layer sustains a large shear stress, which is likely to result in interlayer slip or delamination failure. Therefore, for steel bridge deck pavements at high temperatures and under heavy loads, it is necessary to limit the traffic of heavily loaded vehicles; at the same time, the use of an asphalt waterproof adhesive layer or asphalt pavement layer should be evaluated carefully.

In summary, the shear fatigue life of the waterproof adhesive layer decreases with increasing stress and temperature, and the change rate of the shear fatigue life decreases with increasing stress. In the same stress range, an increase in temperature causes a decrease in the change rate of the shear fatigue life, and it varies only slightly in the range of $-10^{\circ} \mathrm{C}$ to $50^{\circ} \mathrm{C}$. However, when the temperature increases from $50^{\circ} \mathrm{C}$ to $70^{\circ} \mathrm{C}$, the change rate of the 
shear fatigue life decreases sharply. Taking $25^{\circ} \mathrm{C}$ as the boundary, the change rate of the shear fatigue life with temperature can be divided into two stages. At $-10^{\circ} \mathrm{C}$ to $25^{\circ} \mathrm{C}$, the shear fatigue lives at different temperatures have little differences. In contrast, when the temperature is higher than $25^{\circ} \mathrm{C}$, the shear fatigue life decreases sharply. At $70^{\circ} \mathrm{C}$, regardless of the stress value, the shear fatigue life remains small.

\subsubsection{Failure Interface}

The failure states of specimens at different temperatures are shown in Figure 6. At $-10^{\circ} \mathrm{C}$ to $25^{\circ} \mathrm{C}$ (Figure 6A), when the shear displacement of the specimen reaches the failure standard and stops loading, the steel base and pavement mixture do not separate. In contrast, at $50^{\circ} \mathrm{C}-70^{\circ} \mathrm{C}$ (Figure 6B), most of the steel base and pavement mixture have completely separated. Based on the failure interface at different temperatures, the interface of the waterproof adhesive layer can be divided into two parts: steel-waterproof adhesive layer (S-W) and waterproof adhesive layer-pavement (W-P). It can be observed from Figure 6 that the failure interface is not exposed to the surface of the steel base, and a layer of asphalt mixture is attached. This indicates that the failure interface is on the $\mathrm{W}-\mathrm{P}$ part, and the bonding between the epoxy resin waterproof adhesive layer and steel base is very firm.

According to the analysis in Section 3.1, the shear resistance between the waterproof adhesive layer and the pavement layer originates from two factors. The first factor is the bond strength between the waterproof adhesive layer and the pavement mixture. The second factor is the interlocking force between the cured epoxy resin and the bottom interface of the uneven pavement mixture. When the temperature rises to a certain value, the asphalt on the stone surface at the bottom of the steel deck pavement will soften.

Subsequently, the bond strength between the asphalt and cured epoxy resin decreases significantly. This leads to a decrease in the shear resistance of the interface, which correspondingly reduces the shear fatigue life significantly. It can be seen from Figure 6B that some brown waterproof adhesive and part of the asphalt mixture are distributed on the surface of the steel base. This proves that the separated interface is the $\mathrm{W}-\mathrm{P}$ portion. In addition, some white breakstone in the waterproof adhesive layer can be found at the bottom of the damaged pavement mixture. Therefore, during the loading process, the uneven interface between the asphalt mixture and waterproof adhesive is damaged when it resists the shear stress. This confirms that the interlocking force between the two materials makes an important contribution to the interfacial shear resistance. Chang et al. (2016) found that in the specimens damaged at high temperature, the pavement softened and the fracture surface was uneven, and a large amount of asphalt mixture adhered to the interface of the waterproof adhesive layer, which is consistent with the findings of this paper. Zhang and Ye (2014) reported that the fatigue resistance of the interface depends on the adhesive force of the waterproof adhesive layer and the frictional resistance between the layers, which is similar to the results obtained in this paper.

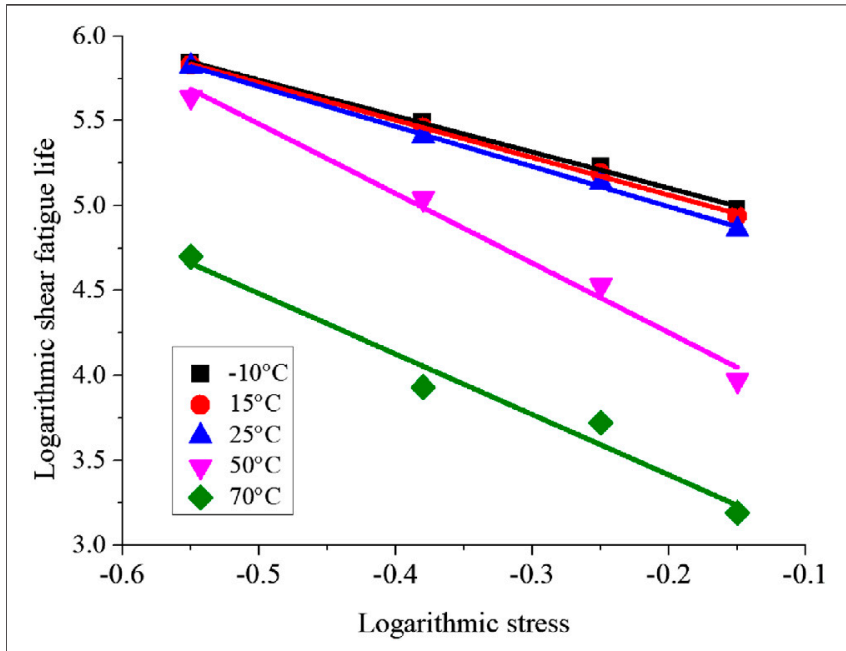

FIGURE 7 | Shear fatigue life diagram under a log-log coordinate.

Currently, most researchers generally refer to the waterproof adhesive layer interface as the steel-asphalt interface (Yao et al., 2016; Liu et al., 2018). Considering the experimental results of this study, this nomenclature is inaccurate. If the waterproof adhesive layer is asphalt material and the pavement material is an asphalt mixture, the high mixture temperature during the construction of the pavement mixture will integrate the asphalt waterproof adhesive layer and the asphalt mixture at the bottom of the pavement. Therefore, the shear resistance of the interface mainly originates from the bond strength between the steel plate and the asphalt waterproof adhesive layer, which can be called the steel-asphalt interface. However, this nomenclature is not accurate in the case of the epoxy resin thermosetting waterproof adhesive layer used in this study, because there are two interfaces between the steel and asphalt, specifically the S-W and $\mathrm{W}-\mathrm{P}$ interfaces. The shear resistance of the $\mathrm{W}-\mathrm{P}$ interface includes the bond force between the waterproof adhesive layer and pavement layer as well as the interlocking force between the cured waterproof adhesive layer and the asphalt mixture.

\subsubsection{Fatigue Equation}

The relationship between the stress and shear fatigue life is linear in a double logarithmic coordinate (Wang et al., 2018), as shown in Eq. 3 and Figure 7.

$$
\lg N_{S F}=a-b \lg \tau
$$

where $\lg N_{S F}$ is the logarithmic shear fatigue $\operatorname{life}, \lg \tau$ is the logarithmic stress, $\tau$ is the stress $(\mathrm{MPa})$, and $a$ and $b$ are parameters.

The prediction models for temperature and shear fatigue life are presented in Table 5. It can be observed that the slopes of the three fitting lines under low and normal temperatures $\left(-10^{\circ} \mathrm{C}\right.$, $15^{\circ} \mathrm{C}$, and $25^{\circ} \mathrm{C}$ ) are almost the same. In addition, the slopes of the two fitting lines in the high-temperature region $\left(50^{\circ} \mathrm{C}\right.$ and $\left.70^{\circ} \mathrm{C}\right)$ are similar. However, the slope at $25^{\circ} \mathrm{C}$ is significantly different from that at $50^{\circ} \mathrm{C}$. The results of covariance analysis with $95 \%$ 
TABLE 5 | Shear fatigue life prediction models for different temperatures.

\begin{tabular}{|c|c|c|c|}
\hline $\begin{array}{l}\text { Temperature } \\
\text { ('C) }\end{array}$ & Fitting equation & Predictive models & $R^{2}$ \\
\hline-10 & $\begin{aligned} \lg N_{S F}= & 4.670-2.143 \\
& \lg \tau\end{aligned}$ & $\begin{array}{c}N_{S F}=46,773.514(\tau)^{-} \\
2.143\end{array}$ & 0.995 \\
\hline 15 & $\begin{aligned} \lg N_{S F}= & 4.617-2.210 \\
& \lg \tau\end{aligned}$ & $\begin{array}{c}N_{S F}=41,399.967(\tau)^{-} \\
2.210\end{array}$ & 0.997 \\
\hline 25 & $\begin{aligned} \lg N_{S F}= & 4.517-2.367 \\
& \lg \tau\end{aligned}$ & $\begin{array}{c}N_{S F}=32,885.163(\tau)^{-} \\
2.367\end{array}$ & 0.996 \\
\hline 50 & $\begin{aligned} \lg N_{S F}= & 3.420-4.115 \\
& \lg \tau\end{aligned}$ & $N_{S F}=2,630.270(\tau)^{-4.115}$ & 0.979 \\
\hline 70 & $\begin{aligned} \lg N_{S F}= & 2.682-3.600 \\
& \lg \tau\end{aligned}$ & $N_{S F}=480.839(\tau)^{-3.600}$ & 0.959 \\
\hline
\end{tabular}

confidence interval (Table 6) confirmed this significant difference.

To establish a unified shear fatigue life equation that considers the effects of temperature and stress, the temperature range was divided into $-10^{\circ} \mathrm{C}$ to $25^{\circ} \mathrm{C}$ and $25^{\circ} \mathrm{C}-70^{\circ} \mathrm{C}$ to modify the shear fatigue equation (Wang et al., 2017; Fang et al., 2019). Setting $-10^{\circ} \mathrm{C}$ and $25^{\circ} \mathrm{C}$ as the standard temperatures, $N_{\text {SFTO }}$ was defined as the shear fatigue life at $-10^{\circ} \mathrm{C}$ or $25^{\circ} \mathrm{C}$. $N_{S F T}$ was defined as the shear fatigue life at any temperature $T$. Based on $N_{S F}=46,773.514(\tau)^{-2.143}$ at $-10^{\circ} \mathrm{C}$ and $N_{S F}=32,885.163(\tau)^{-2.367}$ at $25^{\circ} \mathrm{C}$, it was found that there is a good linear relationship between $N_{S F T} / N_{S F T O}$ and $T / T_{0}$ in the two temperature ranges based on data fitting using the Origin software, as indicated in Eq. 4, where $a$ and $b$ are temperature correction factors for shear fatigue life.

$$
\frac{N_{S F}}{N_{S F 0}}=a-b\left(\frac{T}{T_{0}}\right)
$$

After calculating the $N_{S F T} / N_{S F T O}$ and $T / T_{0}$ in the two temperature ranges and fitting using the Origin software, the shear fatigue lives at $-10^{\circ} \mathrm{C}$ to $25^{\circ} \mathrm{C}$ and $25^{\circ} \mathrm{C}-70^{\circ} \mathrm{C}$ were obtained (Eq. 5):

$$
\left\{\begin{array}{cc}
N_{S F T}=(0.966-0.0042 T) \times 44773.15 \tau^{-2.143} & -10 \leq T<25 \\
N_{S F T}=(1.506-0.021 T) \times 32885.16 \tau^{-2.367} & 25 \leq T \leq 70
\end{array}\right.
$$

\subsection{Effect of Adhesive Quantity on Shear Fatigue Life}

The shear fatigue life curves at different temperatures and coating quantity of the waterproof adhesive layer are presented in Figure 8.

As shown in Figure 8A, the shear fatigue life at the same temperature increases with the coating quantity of the ER waterproof adhesive layer. From Figure 8B, the shear fatigue life decreases with any increase in temperature under different coating quantities of the adhesive. The change rate of the shear fatigue life depends on the shear fatigue life per unit of the coating quantity, as presented in Table 7. The results show that the fatigue life increases rapidly when the coating quantity is small. With increasing coating quantity, the increasing trend of the shear fatigue life tends to become stable and is generally linear. The fatigue life increases faster at low temperatures than at high temperatures. Moreover, within the range of $0.9-1.7 \mathrm{~kg} / \mathrm{m}^{2}$, a linear relationship between the quantity of the waterproof adhesive layer and shear fatigue life is observed. The equations are shown in Figure 8A. Here, $N_{S F}$ is the shear fatigue life and $D_{w b l}$ is the quantity of the waterproof adhesive layer.

It should be noted that when the coating quantity of the waterproof adhesive layer increases, the change trends of the shear fatigue life and shear strength differ. As mentioned in Section 3.1, the shear strength reaches the maximum value at $1.3 \mathrm{~kg} / \mathrm{m}^{2}$ and remains essentially unchanged with increase in the coating quantity. In contrast, as described in this section, the shear fatigue life increases continuously with increasing coating quantity.

One possible reason is the use of the Superpave gyratory compactor in the shear fatigue test. In the process of compaction, the waterproof adhesive was fully bonded with the loose asphalt mixture and compacted. With the continuous increase in coating quantity of the waterproof adhesive, part of the excess waterproof adhesive penetrated into the air voids of the asphalt mixture forming a "hybrid layer" composed of epoxy resin and asphalt mixture. Yao et al. also observed the infiltration of waterproof adhesive into the pavement mixture (Yao et al., 2016). The cured epoxy resin could have increased the strength of the "hybrid layer," which in turn might have reduced the shear fatigue damage in each stress cycle, i.e., the shear fatigue dissipated energy would have been reduced. Hence, the shear fatigue resistance increased gradually. However, the above hypothesis requires further experimental verification.

\section{CONCLUSION}

In this study, shear strength tests and direct shear fatigue tests were performed to analyze the influence of temperature, stress, and coating quantity of the waterproof adhesive layer on the shear fatigue performance of a steel bridge deck pavement with SMA as the pavement layer and epoxy resin as the waterproof adhesive layer. The conclusions are as follows:

TABLE 6 | Differential analysis of the slope of fitted equation.

\begin{tabular}{lcccrc}
\hline Significant difference & \multicolumn{5}{c}{ Temperature $\left({ }^{\circ} \mathbf{C}\right)$} \\
\cline { 2 - 5 } & $\mathbf{- 1 0}$ and $\mathbf{1 5}$ & $\mathbf{1 5}$ and $\mathbf{2 5}$ & $\mathbf{2 5}$ and $\mathbf{5 0}$ & $\mathbf{5 0}$ and $\mathbf{7 0}$ & $\mathbf{2 5}$ and $\mathbf{7 0}$ \\
\hline$P$ & 0.571 insignificant & 0.222 insignificant & 0.008 significant & 0.375 insignificant
\end{tabular}




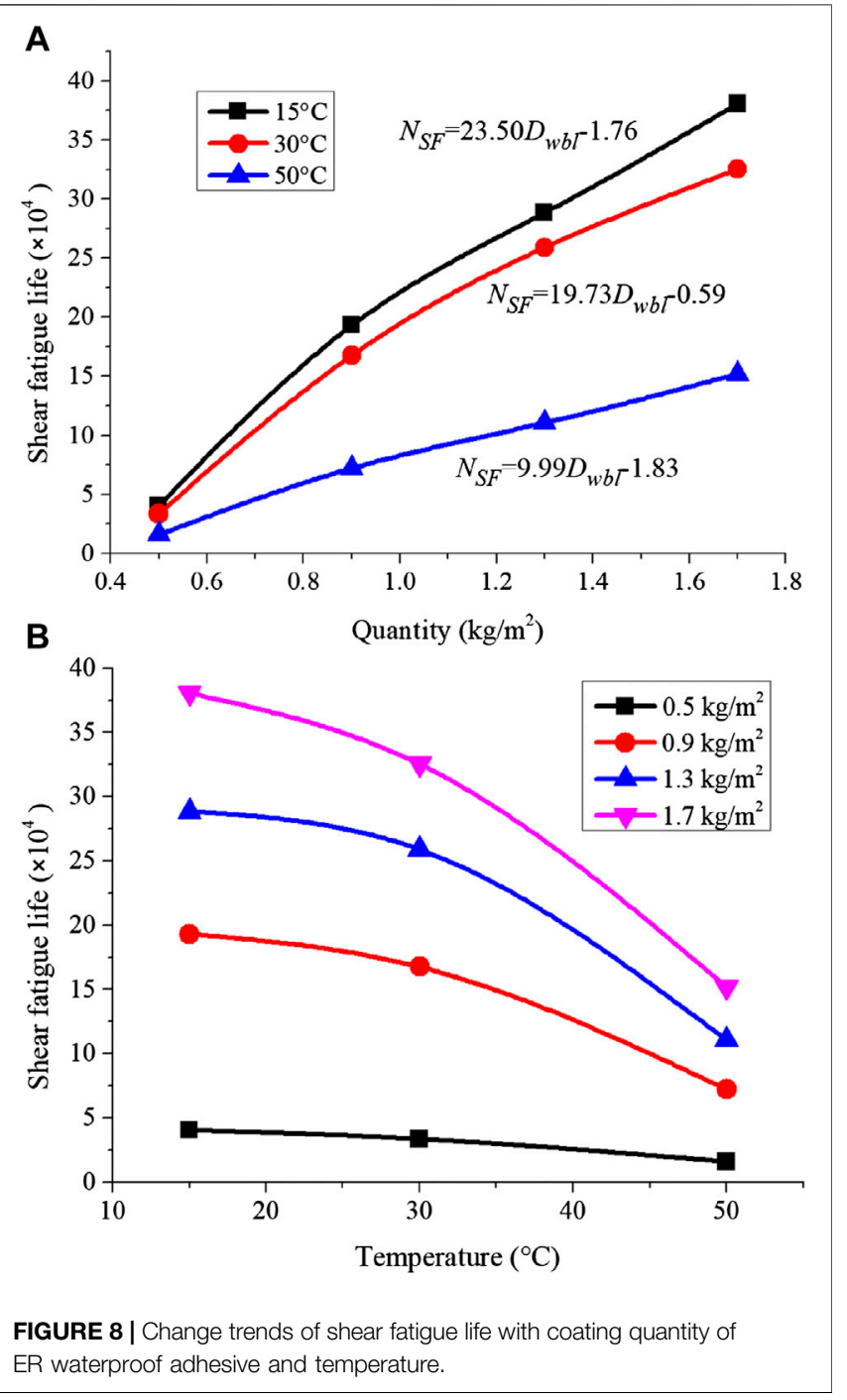

(1) Temperature and stress have significant effects on the shear fatigue life. When the temperature reaches $50^{\circ} \mathrm{C}$, the interlaminar shear fatigue life of the pavement structure decreases sharply. Taking $25^{\circ} \mathrm{C}$ as the boundary, the change rate of the shear fatigue life with temperature can be divided into two stages. At $-10^{\circ} \mathrm{C}$ to $25^{\circ} \mathrm{C}$, the shear fatigue lives at different temperatures have little differences. In contrast, when the temperature is higher than $25^{\circ} \mathrm{C}$, the shear fatigue life decreases sharply. At $70^{\circ} \mathrm{C}$, regardless of the stress value, the shear fatigue life remains small. Therefore, for steel bridge deck pavements subjected to high temperatures and heavy loads, it is necessary to limit the traffic of heavily loaded vehicles. In addition, the use of an asphalt waterproof adhesive layer or asphalt pavement layer should be evaluated intensively.

(2) Temperature and stress have a linear relationship with shear fatigue life on a double logarithmic coordinate. The final
TABLE 7 | Change rate of shear fatigue life with coating quantity $\left(\times 10^{4} \mathrm{~m}^{2} / \mathrm{kg}\right)$.

\begin{tabular}{lccc} 
Temperature $\left({ }^{\circ} \mathbf{C}\right)$ & \multicolumn{3}{c}{ Coating quantity $\left(\mathbf{k g} / \mathbf{m}^{\mathbf{2}}\right)$} \\
\cline { 2 - 4 } & $\mathbf{0 . 5 - 0 . 9}$ & $\mathbf{0 . 9 - 1 . 3}$ & $\mathbf{1 . 3 - 1 . 7}$ \\
\hline 15 & 38.15 & 23.88 & 23.04 \\
30 & 33.51 & 22.85 & 16.62 \\
50 & 14.08 & 9.64 & 10.34
\end{tabular}

predictive model of shear fatigue life is obtained by temperature correction and data fitting.

(3) The interface of the epoxy resin waterproof adhesive layer can be divided into two parts: steel plate-waterproof adhesive layer (S-W) and waterproof adhesive layer-pavement (W-P). The damage interface of shear fatigue at different temperatures always occurs at the $\mathrm{W}-\mathrm{P}$ interface. The shear strength of the epoxy resin waterproof adhesive layer is mainly provided by the bond strength between the waterproof adhesive and pavement mixture as well as the interlocking force between the cured epoxy resin and the bottom interface of the uneven pavement mixture.

(4) With an increase in the quantity of the epoxy resin waterproof adhesive layer, the shear strength first increases to the optimal value $(2.11 \mathrm{MPa})$ and then stabilizes, whereas the shear fatigue life increases continuously. Therefore, increasing the thickness of the waterproof adhesive layer is beneficial for resisting the interlayer shear fatigue failure.

\section{DATA AVAILABILITY STATEMENT}

The raw data supporting the conclusions of this article will be made available by the authors, without undue reservation.

\section{AUTHOR CONTRIBUTIONS}

YX and XL: Writing-original draft preparation, methodology, writing-review and editing. XL, CM, FL, JQ, and ZC: The data curation. YX and SX: Supervision, project administration and funding acquisition. All authors contributed to the article and approved the submitted version.

\section{FUNDING}

This work was funded by the Science and Technology Project of the Beijing Municipal Education Commission (Grant No. SQKM201810016003), the Beijing Advanced Innovation Center for Future Urban Design (Grant No. UDC2019032624), and the research project of the Nation Natural Science Foundation of China (Grant No. 51978035). 


\section{REFERENCES}

Bocci, E., and Canestrari, F. (2012). Analysis of structural compatibility at interface between asphalt concrete pavements and orthotropic steel deck surfaces. J. Transport. Res. Rec. Board. 2293 (1), 1-7. doi:10.3141/2293-01

Bocci, E., and Canestrari, F. (2013). Experimental evaluation of shear resistance of improved steel-asphalt interfaces. J. Transport. Res. Rec. Board. 2370 (2370), 145-150. doi:10.3141/2370-18

Boudabbous, M., Millien, A., Petit, C., and Neji, J. (2013). Energy approach for the fatigue of thermoviscoelastic materials: application to asphalt materials in pavement surface layers. Int. J. Fatig. 47 (FEB), 308-318. doi:10.1016/j. ijfatigue.2012.09.013

Chang, Y., Chen, Z., and Zhang, Z. (2016). Shear fatigue performance of epoxy emulsified asphalt adhesive layer. J. Jiangsu Univ. (Nat. Sci. Ed.). 2016 (3), 342-346 [in Chinese]. doi:10.3969/j.issn.1671-7775.2016.03.016

Chen, L., Qian, Z., Chen, D., and Wei, Y. (2020). Feasibility evaluation of a long-life asphalt pavement for steel bridge deck. Adv. Civ. Eng. 2020, 1-8. doi:10.1155/ 2020/5890945

Chen, S., and Zhang, H. (2004). Research and development of SMA Pavement Technology for steel bridge deck. Highway Transp. Technol. 21 (10), 5-8 [in Chinese]. doi:10.3969/j.issn.1002-0268.2004.10.002

Chou, Z. (2020). Analysis and optimization of steel deck pavement structure under various fatigue damage behaviors[D]. Beijing University of Civil Engineering and Architecture, Beijing, China, (in Chinese)

Diakhate, M., Phelipot, A., Millien, A., and Petit, C. (2006). Shear fatigue behaviour of tack coats in pavements. Road Mater. Pavement Des. 7, 201-222. doi:10.1080/ 14680629.2006.9690033

Diakhate, M., Millien, A., Petit, C., Phelipot-Mardele, A., and Pouteau, B. (2011). Experimental investigation of tack coat fatigue performance: towards an improved lifetime assessment of pavement structure interfaces. Construct. Build. Mater. 25 (2), 1123-1133. doi:10.1016/j.conbuildmat.2010.06.064

Fang, N., Wang, X., Ye, H., Sun, Y., and Yuan, L. (2019). Study on fatigue characteristics and interlayer design method of waterproof cohesive bridge deck layer. Appl. Sci. 9 (10), 2090. doi:10.3390/app9102090

Ge, Z., Wang, Y., and Hang, M. (2014). New device and methodology for evaluating the shear behavior of steel bridge deck pavement pasted by gfrp sheets. J. Test. Eval. 42 (1), 20120343. doi:10.1520/JTE20120343

JTG T3364-02-2019. (2019). Specifications for design and construction of pavement on highway steel deck bridge. Beijing: Ministry of Transport of the People's Republic of China.

JTG E20-2011. (2011). Standard test methods of bitumen and bituminous mixtures for highway engineering. Beijing: Ministry of Transport of the People's Republic of China.

$\mathrm{Li}, \mathrm{H}$., and $\mathrm{Yu}, \mathrm{B}$. (2014). Fatigue performance and prediction model of multilayer deck pavement with different tack coat materials. J. Mater. Civ. Eng. 26 (5), 872-877. doi:10.1061/(ASCE)MT.1943-5533.0000895

$\mathrm{Li}, \mathrm{S}$., Liu, X., and Liu, Z. (2014). Interlaminar shear fatigue and damage characteristics of asphalt layer for asphalt overlay on rigid pavement. Construct. Build. Mater. 68 (oct.15), 341-347. doi:10.1016/j.conbuildmat.2014.06.053

Liu, X., Feng, D., Tang, H., Zhou, C., and Li, J. (2016). Investigation on the bending fatigue and shear failure in steel bridge deck pavement systems. J. Test. Eval. 44 (2), 20150236. doi:10.1520/JTE20150236

Liu, X., Zhou, C., Feng, D., Fan, X., and Xie, S. (2017). Experimental study on interlayer shear properties of ERS pavement system for long-span steel bridges. Construct. Build. Mater. 143, 198-209. doi:10.1016/j.conbuildmat. 2017.03.144
Liu, Y., Yao, B., Yu, C., Wu, J., Chen, J., and Zhang, L. (2018). Experimental evaluation of the shear performance of steel-asphalt interface considering temperature and humidity coupling. Int. J. Adhesion Adhes. 84, 360-367. doi:10.1016/j.ijadhadh.2018.04.011

Medani, T. O. (2001). Asphalt surfacing applied to orthotropic steel bridge decks (Report 7-01-127-1). Delft, The Netherlands: TU Delft.

Medani, T. O., Liu, X., Huurman, M., Scarpas, A., and Molenaar, A. A. A. (2008). Experimental and numerical characterization of a membrane material for orthotropic steel deck bridges: part 1: experimental work and data interpretation. Finite Elem. Anal. Des. 44 (9-10), 552-563. doi:10.1016/j. finel.2008.01.013

Qiu, Y., An, S., Rahman, A., and Ai, C. (2019). Evaluation and optimization of bridge deck waterproof bonding system using multi-objective grey target decision method. Road Mater. Pavement Des., 1-15. doi:10.1080/14680629. 2019.1568288

Rahman, A. A., Huang, H., Ding, H., Xin, C., and Lu, Y. (2019). Fatigue performance of interface bonding between asphalt pavement layers using four-point shear test set-up. Int. J. Fatig. 121, 181-190. doi:10.1016/j. ijfatigue.2018.12.018

Shen, C., Gao, P., and Zhang, H. (2018). Research on temperature field of steel deck pavement by finite element. Highw. Eng. 43 (3), 21-25 [in Chinese].

Song, W., Shu, X., Huang, B., and Woods, M. (2016). Laboratory investigation of interlayer shear fatigue performance between open-graded friction course and underlying layer. Construct. Build. Mater. 115 (jul.15), 381-389. doi:10.1016/j. conbuildmat.2016.04.060

Tozzo, C., Fiore, N., and D'Andrea, A. (2014). Dynamic shear tests for the evaluation of the effect of the normal load on the interface fatigue resistance. Construct. Build. Mater. 61 (jun.30), 200-205. doi:10.1016/j. conbuildmat.2014.03.010

Wang, X., Fang, N., Ye, H., and Zhao, J. (2018). Fatigue damage analysis of cementstabilized base under construction loading. Applied Ences. 8 (11), 2263. doi:10. 3390/app8112263

Wang, X., Su, Z., Xu, A., Zhou, A., and Zhang, H. (2017). Shear fatigue between asphalt pavement layers and its application in design. Construct. Build. Mater. 135 (MAR.15), 297-305. doi:10.1016/j.conbuildmat.2016.12.151

Yao, B., Li, F., Wang, X., and Cheng, G. (2016). Evaluation of the shear characteristics of steel-asphalt interface by a direct shear test method. Int. J. Adhesion Adhes. 68, 70-79. doi:10.1016/j.ijadhadh.2016.02.005

Zhang, H., and Ye, J. (2014). Research on the effect of interface contact conditions on the interlayer fatigue performance of concrete bridge deck pavement structure highway and transportation science and technology. Appl. Technol. Ed. 6 [in Chinese], 347-348. doi:10.3969/j.issn.1674-0610.2018.03.005

Conflict of Interest: Authors CM, FL, and JQ were employed by company Henan Taihui Expressway Construction Co., Ltd.

The remaining authors declare that the research was conducted in the absence of any commercial or financial relationships that could be construed as a potential conflict of interest.

Copyright $\odot 2021 X u, L v, M a$, Liang, Qi, Chou and Xu. This is an open-access article distributed under the terms of the Creative Commons Attribution License (CC BY). The use, distribution or reproduction in other forums is permitted, provided the original author(s) and the copyright owner(s) are credited and that the original publication in this journal is cited, in accordance with accepted academic practice. No use, distribution or reproduction is permitted which does not comply with these terms. 